\title{
Eu gosto da escola: um estudo sobre o apego ao ambiente escolar
}

\author{
Pollyana Verissimo de Araújo \\ Universidade Federal da Paraíba - João Pessoa - PB - Brasil \\ Viviany Silva Pessoa \\ Universidade Federal da Paraíba - João Pessoa - PB - Brasil \\ Patricia Nunes da Fonseca \\ Universidade Federal da Paraíba - João Pessoa - PB - Brasil \\ Juliana Henrique de Assis Albuquerque \\ Universidade Federal da Paraíba - João Pessoa - PB - Brasil \\ Aline Carvalho de Almeida \\ Universidade Federal da Paraíba - João Pessoa - PB - Brasil
}

\begin{abstract}
Resumo
O presente artigo teve como objetivo analisar o nível de apego dos alunos ao ambiente escolar. Para tanto, adotou-se a perspectiva da relação pessoa-ambiente que busca contribuir para a vertente institucional da psicopedagogia. Participaram do estudo 200 alunos do ensino médio, com idade média de 15,15 $(D P=0,98)$, igualmente distribuídos entre escolas públicas e privadas de uma capital nordestina. Estes responderam à Escala Apego ao Lugar, além de questões sociodemográficas. As análises indicaram que o nível de apego à escola foi considerável em relação ao esperado, evidenciando uma diferença significativa do nível de apego ao lugar em função do tipo de sistema de ensino $(t(191)=-2,205 ; p \leq 0,03)$, com destaque para a escola privada $(M=3,36 ; D P=0,603)$. Com base nesses resultados, foi possível discutir a necessidade de desenvolver estratégias voltadas para promoção de identidade com a escola, percepção da escola como comunidade e atitudes positivas frente à escola.
\end{abstract}

Palavras-chave: Comportamento de apego; ambiente escolar; estudantes.

\section{I like school: a study on the attachment to the school environment}

\begin{abstract}
This article aims to analyze the attachment level of students to the school environment. Therefore, it adopted the perspective of the personenvironment relationship that seeks to contribute to the institutional aspect of educational psychology. Participants were 200 high school students with an average age of $15.15(\mathrm{SD}=0.98)$, equally distributed between public and private schools in a northeastern capital. They answered to Attachment Place Scale to place in attachment to sociodemographic questions. The analyzes indicated that the level of addiction to school has been achieved in relation to the expected, showing a significant difference in the level of attachment to place depending on the type of education system $(t(191)=-2.205 ; p \leq 0,03)$, especially the private school $(M=3.36, S D=0.603)$. Based on these results, it was possible to discuss the need to develop focused strategies to promote identity with the school, the school as a community perception and positive attitudes to school.
\end{abstract}

Keywords: Attachment behavior; school environment; students.

\section{Me gusta la escuela: un estudio sobre el apego al ambiente escolar}

\section{Resumen}

El presente artículo tuvo como objetivo analizar el nivel de apego de los alumnos al ambiente escolar. Para tanto, se adoptó la perspectiva de la relación persona-ambiente que busca contribuir para la vertiente institucional de la psicopedagogía. Participaron del estudio 200 alumnos de la enseñanza secundaria, con edad media de 15,15 $(D P=0,98)$, igualmente distribuidos entre escuelas públicas y privadas de una capital nordestina. Éstos contestaron a la Escala Apego al Lugar además de cuestiones sociodemográficas. Los análisis indicaron que el nivel de apego a la escuela fue considerable en relación al esperado, evidenciando una diferencia significativa del nivel de apego al lugar en función del tipo de sistema de enseñanza $(t(191)=-2,205 ; p \leq 0,03)$, con destaque para la escuela privada $(M=3,36 ; D P=0,603)$. Con base en esos resultados, fue posible discutir sobre la necesidad de desarrollar estrategias volcadas para promoción de identidad con la escuela, percepción de la escuela como comunidad y actitudes positivas frente a la escuela.

Palabras clave: Conducta de apego; ambiente escolar; estudiantes. 


\section{Introdução}

O Século XXI tem início com reformulações nos mais diversos setores, como na tecnologia com o surgimento dos computadores, telefones celulares e internet (Balarine, 2002). A sociedade ganhou novas visões de mundo e leis que também repercutiram na educação, na qual é possível observar, por exemplo, a implementação de leis de inclusão e a expansão de conhecimentos entre a população. Ainda com o foco na educação, essas reformulações ganham uma importância particular, se considerarmos que no século anterior o ponto central da educação era a rigidez frente ao ensino e à formação do sujeito, ao passo que ao longo do tempo foram estabelecidas modificações nas três categorias fundamentais: a escola, o professor e o estudante (Faria \& Casagrande, 2004) e, dentre elas, mudanças frente às interações.

Atualmente, dentro do universo escolar, uma das preocupações é pensar novas estratégias para atender às demandas do processo de aprendizagem e às suas dificuldades. Muito se tem feito para que as problemáticas relacionadas ao processo ensino-aprendizagem sejam combatidas, sejam elas nos âmbitos individual, social e institucional. Áreas como a pedagogia, a Psicologia e a Psicopedagogia têm se dedicado a estudos que atendem a esse fim (Porto, 2011).

De acordo com Oliveira-Silva (2008), os processos de aprendizagem estão associados a fatores tanto de forma implícita e individual como de forma explícita, sociocultural e ambiental. Dentre esses fatores, foi possível encontrar estudos que destacam os laços criados com o ambiente chamado escola e as implicações dessa relação para a formação geral do sujeito (Cunha, 2013).

O interesse deste artigo é, portanto, destacar o nível de afetividade do estudante com o seu ambiente escolar, tendo como princípio psicopedagógico os aspectos socioculturais e ambientais associados ao processo de aprendizagem em uma perspectiva institucional. Neste sentido, considera-se que a relação pessoa-ambiente oferece elementos que podem repercutir positiva ou negativamente no processo de ensino-aprendizagem e de desenvolvimento humano. A partir deste princípio, é possível estabelecer uma relação com os aspectos de formação humana desde o âmbito escolar e os aspectos afetivos frente ao espaço escolar. Desse modo, é interessante conhecer o nível de apego do estudante frente à escola e aos seus ambientes constituintes, visto que o apego ao ambiente escolar ou acadêmico pode trazer implicações significativas ao crescimento pleno do usuário desse tipo de espaço ( $\mathrm{Li}, 2011)$.

É importante compreender os estudos que interligam o apego, a instituição escolar e a aprendizagem, pois através de uma análise sobre o nível de apego dos discentes ao ambiente escolar é possível reunir dados que auxiliam na compreensão e explicação de atitudes, autenticidades, fracassos, sucessos, ideias, objetivos, potencialidades e limitações e, a partir daí, poder propor metodologias e estratégias de ação capazes de favorecer não apenas o de- senvolvimento cognitivo como também o desenvolvimento social e emocional dos estudantes (Bossa, 2011).

Mas como se apresenta o panorama de publicações relacionadas a essa questão? Buscas foram realizadas a partir de livros, artigos, revistas científicas e por meio da internet. Os materiais encontrados destacam a relação pessoa-ambiente (Günther, Nepomuceno, Spehar, \& Günther, 2003; Giuliani, 2004), apego ao lugar (Alencar, 2007; $\mathrm{Li}, 2011$ ), laços afetivos criado com lugares (Scannell \& Gifford, 2009; Felippe \& Kuhnen, 2012), o ambiente escolar e suas diversidades (Dayrell, 2007), barulho, conversa e temperatura (Libardi \& cols. 2006), ambiente tedioso e falta de motivação (Eccheli, 2008). E, embora seja um levantamento breve, forneceu um sinalizador dessa discussão na realidade brasileira e estrangeira.

Diante desse contexto, o presente artigo trouxe a hipótese de que há variação no nível de apego dos estudantes frente ao ambiente escolar. Nesse sentido, traçou-se como objetivo principal analisar o nível de apego dos alunos ao ambiente escolar. Além disso, os objetivos específicos buscaram: 1) verificar se existe diferença em função do sexo e 2) verificar se existe diferença do nível de apego em função do sistema de ensino público e particular.

\section{A escola e seus vínculos}

O contexto escolar é um local de formação humana, convivência e troca de relações (Dessen \& Polonia, 2007); um espaço diversificado de significados históricos, emocionais e sociais, onde estes são essenciais para entender como se desenvolve o processo de aprendizagem, a partir da singularidade de cada aluno (Panizzi, 2010). Em termos estruturais, a escola é vista como um ambiente físico que propicia um contexto dinâmico para os seus usuários e por meio dele várias coisas mudam, como os pensamentos, sentimentos, interações sociais e o bem-estar físico e subjetivo. Esse espaço oferece experiências únicas e primordiais para a vida, pois, a partir do meio ao qual se está inserido, é possível criar vínculos capazes de influenciar escolhas futuras do sujeito (Sutton \& Kemp, 2002).

De acordo com a Lei de Diretrizes e Bases da Educação Brasileira (Lei n 9394, 1996), a escola deve ter por fundamento a meta de desenvolver as potencialidades dos alunos a fim de que os mesmos sejam capazes de pensar e agir na realidade social, de forma a exercer a cidadania da maneira mais ampla possível. Nesse sentido, a escola é um espaço educacional responsável pela construção de saberes, formação de trocas de informações entre pessoas, regulação de condutas e interação de indivíduos de diferentes culturas, valores e crenças.

$\mathrm{E}$, mesmo que as primeiras redes comunicativas formadas pelos estudantes sejam fruto dos grupos sociais mais imediatos a exemplo da casa e vizinhança; para só depois serem expandidas para a escola (Cunha, 2013); a escola, ainda assim, é entendida como espaço de formação primordial para a transmissão de novos conhecimentos e saberes, 
por meio de passos evolutivos de uma forma gradativa e eficaz, onde cabe, de algum modo, a esta educação dispor de assuntos complexos e diversificados e, ao mesmo tempo, ser a âncora de novos aprendizados (Delors \& cols., 1998).

Assim, é possível estabelecer que as escolas se configurem como um dos três ambientes distintos e fundamentais para a formação humana. De acordo com Günther e cols. (2003), esses ambientes são: a casa, como um espaço ao qual se aprende os primeiros modelos comportamentais e a visão de mundo que guiará nas escolhas e condutas; os espaços públicos (shoppings, praças, áreas de lazer), onde se promove a internalização de regras, como um dos elementos de aprendizagem e socialização.

É possível observar as interações entre estudante-instituição, e sugerir que os indivíduos que apresentam boas relações com a escola tendem a apresentar ações adequadas tanto frente àquele ambiente quanto frente aos seus usuários frequentadores. Assim, a escola deve ser vista como um ponto fundamental de intersecção no processo de aprendizagem, pois visa oferecer meios para que o usuário se desenvolva de forma integral (Dalbem \& Dell' Aglio, 2005).

\section{Apego ao lugar - escola}

Para compreender melhor o que vem a ser apego ao lugar, é necessária uma breve especificação e diferenciação dos conceitos constituintes do termo, são eles: apego e lugar. Segundo Figueiredo (2010), no novo dicionário de língua portuguesa, apego é afeição, aferro, insistência (de apegar). Para Bowlby (1977), apego seria algo favorável dos seres humanos ao fazerem ligações afetivas fortes com pessoas ou algo específico.

Kaiser e Fuhrer (1996) abordam a teoria do apego como um suporte para a formação de laços ou ligações com ambientes e espaços prazerosos, que satisfazem as necessidades emocionais a partir de frustrações e alegrias que facilitam o desenvolvimento e a reciclagem de identidade como ser humano com uma carga de vivências. Portanto, o mais difícil é entender como os jovens formalizam seu desenvolvimento, procuram novas etapas, buscam novas vivências e, diante do referencial estudado, deliberam ligação de apego e desapego com ambientes.

Segundo Cavalcante e Nóbrega (2011), lugar é um espaço que possui significação e importância pelas relações e emoções envolvidas, enquanto espaço é uma matéria à qual se atribui interação ao indivíduo; no entanto, pode-se dizer neutro já que não possui significado.

Dessa forma, apego ao lugar - ou place attachment como é conhecido na literatura especializada - é um conceito complexo e de várias compreensões, cujo entendimento exige foco para as características físico-espaciais do local e as traduções de simbologia e afetividade que estão relacionadas pelos sujeitos ou grupos (Elali \& Medeiros, 2011).

A literatura baseada no estudo de apego ao lugar (Elali \& Medeiros, 2011) traz a participação de três dimensões fundamentais para o conhecimento do apego, a saber: (a) a dimensão funcional que envolve os elementos contidos em certo espaço, à qual estimula ou inibe os movimentos e gestos realizados neste local; (b) a dimensão simbólica que diz respeito à cultura de cada indivíduo interferindo nas suas relações pessoa-ambiente e no modo como cada um reage frente às diversas situações; e (c) a dimensão relacional que se refere às relações de uma forma dinamizada entre a sociedade e o ambiente ao qual a pessoa pertence. Dimensões que, ao interligar cognitiva e afetivamente pessoas e ambientes, contribuirão na formação da identidade pessoal e societária de cada indivíduo.

De acordo com Felippe e Kuhnen (2012), apego ao lugar pode ser descrito como um sentimento de pertencimento firmado com cenários físicos, envolvendo emoções advindas da experiência real ou esperada do espaço. Discorrem que o apego a determinado ambiente ocorre nas pessoas cuja identidade de lugar envolve pensamentos positivos e valorizados de uma ou alguma mistura destes sentimentos em relação ao lugar, onde, finalmente, pesam mais do que os pensamentos negativos não sendo valorizados. Desta forma, as autoras discutem a questão que as emoções influenciam positiva e negativamente a vida de uma pessoa dependendo do ambiente no qual está inserido; entretanto, é possível relacionar a escola como um espaço de formação acadêmica, afetiva e social, permitindo que cada estudante discorra de suas atitudes e percepções de uma forma objetiva e direta.

Segundo Relph (1970), a ideia de apego a um lugar é vista como uma dependência humana primordial, em que a população contemporânea está cada vez menos possibilitada de realizar, pelo fato de a sua tendência seguir crescentemente com o foco, a única formalidade espacial e uma alta flexibilidade, desenvolvendo, porquanto, uma junção estritamente funcionalista com os lugares.

Alguns dos comportamentos relacionados ao apego ao lugar ou laços afetivos construídos com lugares podem ser definidos quanto à identidade pessoal, o sentido de pertencimento a um lugar e à apropriação e cuidados com ambientes, que é a forma com a qual um indivíduo passa a direcionar atenção ao lugar no sentido de manter um ambiente prazeroso que satisfaça suas necessidades e sua identidade pessoal (Felippe, Raymundo, \& Kuhnen, 2013).

De acordo com Fried (conforme citado por Felippe \& Kuhnen, 2012), a primeira referência objetiva aos laços afetivos com lugares foi feita na obra Grievining for a Lost Home, em que foi possível verificar que o distanciamento do lugar produzia sentimentos semelhantes à perda de uma pessoa próxima e atribuiu essas reações a uma paralisação do sentido de continuidade dos moradores, pela dispersão da identidade espacial e comunitária.

De forma resumida, é possível observar a ideia de apego ao lugar como um viés para as vertentes institucionais, visto que esta ideia contribui de forma positiva ao observar o estudante e suas interações com o meio escolar, o usuário e seu nível de significância para com a escola, o estudante e seus laços afetivos criados com o meio institucional e o aluno e suas potencialidades e fracassos. 


\section{Método}

\section{Delineamento}

O presente estudo caracteriza-se como uma pesquisa transversal, usando a abordagem de levantamento de informações (survey). Para analisar os dados optou-se por métodos estatísticos (análises descritivas e inferenciais), dada à necessidade de análises propostas pelos objetivos para o estudo sobre apego ao lugar.

\section{Participantes}

Contou-se com a participação de 200 estudantes do ensino médio, sendo $43 \%$ meninos e $57 \%$ meninas. A amostra foi distribuída igualmente entre escola pública e particular de ensino de uma capital nordestina. As idades dos participantes variaram entre 14 e 19 anos $(M=15,15 ; D P=0,976)$, tendo a maioria deles se identificado como sendo da classe média (89\%). Quando perguntado o tempo de matrícula na escola, foi verificada uma maior concentração $(54,5 \%)$ entre aqueles que relataram ter entre um a 10 (dez) anos de matrícula na mesma escola, seguido daqueles que relataram ter até um ano de matrícula ( $40 \%)$ e os que relataram ter mais de 10 anos de matrícula na mesma escola $(5,5 \%)$.

\section{Instrumentos}

Para a construção e realização desta pesquisa foram utilizados dois instrumentos em forma de livreto.

Escala de Apego ao Lugar (Place Attachment Scale; Li, 2011):

Este instrumento é unifatorial, composto por 30 itens sendo, 10 referentes à ligação afetiva (e.g. item 1 Sinto-me feliz quando estou na escola), 10 representando os aspectos comportamentais (e.g. item 2 Eu não me importo sobre o que acontece na escola) e 10 referentes aos aspectos cognitivos (e.g.item 3 Eu tenho lembranças significativas da escola). Dos 30 itens apresentados, 11 deles são invertidos $(03,07,09,11,14,15,16,17,19,21,23)$. Além disso, algumas palavras foram modificadas para se ajustar ao contexto institucional (universidade-escola, prédios-áreas). As respostas foram organizadas em uma escala de 1 (Discordo totalmente) a 5 (Concordo totalmente). A medida original apresenta um índice de consistência interna adequada $(\alpha=$ $0,94)$. Na versão adaptada para o contexto escolar em análise, o índice de consistência interna também foi adequado $(\alpha=0,88)$, conformando sua possibilidade de uso. Os itens foram calculados para criar uma pontuação média.

\section{Dados Sociodemográficos}

O questionário era composto por perguntas sobre questões sociodemográficas: tipo de escola, idade, sexo, ren- da familiar estimada, tempo de matrícula na escola, em quantas escolas estudou anteriormente e sala de aula agradável.

\section{Procedimento}

Inicialmente foi apresentado o projeto às instituições escolhidas a fim de solicitar as devidas autorizações para a coleta dos dados, ressaltando-se na oportunidade que o material foi submetido e aprovado pelo Comitê de Ética em Pesquisa com Seres Humanos, do Hospital Universitário Lauro Wanderley, da Universidade Federal da Paraíba (Proc. CEP/HULW no 731401 de 29/07/2014). Após a concordância das escolas, os estudantes foram convidados a participar da pesquisa respondendo a um questionário contendo uma escala, além de questões sociodemográficas. Antes de realizar a aplicação foi informado o caráter voluntário da participação, além do caráter anônimo e confidencial de todas as informações. Uma vez tendo concordado com a participação no estudo, os respondentes assinaram o Termo de Assentamento, baseado nos preceitos éticos vigentes para a realização de pesquisas com seres humanos, defendidos pela Resolução n. 466/12 do CNS/MS. Após explicar todas as dúvidas surgidas foi informado que os resultados ficariam disponíveis para os interessados, desde que estes entrassem em contato com a pesquisadora por meio de mensagem eletrônica. O questionário foi aplicado em contexto coletivo de sala de aula, mas respondido de forma independente por cada participante e teve uma duração média de 20 minutos.

\section{Análise dos dados}

Os dados foram analisados de forma quantitativa por meio do programa estatístico SPSS (Statistical Package for the Social Science 21), que possibilitou caracterizar o grupo amostral (média, desvio-padrão e percentuais), conhecer o nível de apego que os estudantes afirmaram ter pela escola (médias); verificar diferenças entre escola pública e particular, e entre meninos e meninas (teste $t$ de Student).

\section{Resultados}

Os resultados são apresentados em subtópicos, organizados de acordo com o tipo de análise empregada para o tratamento de dados. Diante disso, inicialmente, são apresentados os resultados para as questões gerais, voltadas para a relação do estudante com a escola, assim como o nível de apego ao lugar apresentado pelos participantes. $\mathrm{Na}$ sequência, são apresentados os resultados relativos às questões sociodemográficas, resultados referentes à comparação entre os grupos (masculino e feminino) e, por fim, a comparação entre os sistemas de ensino (público e particular). 


\section{Resultados relativos à média de apego ao lugar}

Os dados coletados obtiveram como média geral $(M$ $=3,28 ; D P=0,561$ ), o que indica um nível de apego ao lugar - escola interessante. $O$ estudo original também apresentou uma média $(M=3,91)$ considerável (Li, 2011). Mesmo com esses indicadores, estudos anteriores discutem uma realidade em que a escola é identificada como um dos lugares menos apreciados pelos adolescentes (Günther\& cols., 2003).

Com base nesses dados, é possível se discutir sobre a necessidade da promoção de vínculos afetivos. Além disso, faz-se necessário pensar em estratégias de ações que auxiliem a construção e fortalecimento do sentimento de identidade do aluno para com a escola. De acordo com Li (2011), o apego ao lugar é um fenômeno que pode contribuir para o senso de responsabilidade das pessoas. Ou seja, quanto mais sensação de apego o estudante tiver, mais ele poderá contribuir com aquele local. Com isso, entende-se que o apego ao lugar, uma vez promovido, pode estar implicado em desdobramentos positivos da vida estudantil.

\section{Resultados relativos às questões sociodemográficas}

Do total de participantes do estudo, $55 \%$ consideram sua sala de aula agradável e $45 \%$ apresentaram razões para não achar sua sala de aula agradável, tais como: barulho $2 \%$, bagunça $6 \%$, conversa $2 \%$, relações interpessoais $8,5 \%$, falta de motivação $2,5 \%$, temperatura $14 \%$, sujeira $2,5 \%$, conforto $4 \%$, falta de infraestrutura $10 \%$, ambiente tedioso $2,5 \%$. Relataram ter estudado em mais de duas escolas anteriormente (55\%), já $27,5 \%$ disseram ter estudado em duas escolas; $13 \%$ informaram ter estudado em apenas uma escola e $4 \%$ relataram não ter estudado em nenhuma escola anteriormente.

Quanto às categorias como barulho, conversa e temperatura, a literatura aponta uma discussão pertinente, a exemplo do estudo de Ribeiro e cols. (2010), que discute vários problemas relacionados à qualidade do ambiente escolar e à qualidade do ensino nesse espaço. Essas autoras indicam que algumas características importantes como a temperatura, circulação de ar e ambiente sonoro estão sendo revelados como fatores importantes para uma má concentração em sala de aula. A pouca informação relacionada ao barulho em sala de aula se torna preocupante, pelo fato de que se houvesse o conhecimento, seria possível identificar, minimizar e até erradicar as interferências negativas que um ambiente acusticamente inadequado e ruidoso pode trazer para o processo de ensino-aprendizagem e à saúde de professores e usuários (Klodzinski, Arnas, \& Ribas, 2005).

Alguns efeitos negativos decorrentes dos ruídos em sala de aula são: dificuldade dos usuários compreenderem a fala dos professores e vice versa, diminuição da concentração e atenção dos estudantes nas aulas, irritabilidade ou estresse por parte dos docentes e discentes, falta de com- preensão das falas e má absorção e seleção das informações obtidas em sala de aula (Ribeiro \& cols., 2010).

Quanto às categorias nomeadas como falta de motivação e ambiente tedioso, é possível discutir que a motivação no âmbito institucional tem sido avaliada como um fator determinante para a qualidade e o desempenho da aprendizagem. De acordo com Guimarães e Boruchovitch (2004), um usuário motivado torna-se dinamicamente envolvido no processo de aprendizagem, participando e colaborando em tarefas de grandes exigências, despendendo esforços, usando métodos adequados, tentando desenvolver novas estratégias de compreensão e domínio. As descobertas sobre as orientações autodeterminadas motivacionais, ou seja, a motivação que o estudante revela de forma individual ao longo do seu envolvimento com a escola, e as formas motivacionais que os usuários apresentam através de fatores externos e oferecidos pelo ambiente escolar, representam alternativas de envolvimento dos estudantes com a escola e com sua própria educação (Guimarães \& Boruchovitch, 2004).

Quanto às categorias: relações interpessoais, falta de motivação, temperatura, falta de infraestrutura e ambiente tedioso, não foi possível descrevê-los de forma mais sucinta, devido à escassez de materiais e base da literatura, deixando a desejar um trabalho mais completo e rico de informações.

\section{Resultados relativos à comparação do nível de apego ao lugar em função do sexo}

Os resultados seguem com a análise de comparação, com o fim de atender a um dos objetivos específicos do estudo, que é comparar o nível de apego ao lugar em função do sexo. Por conseguinte, preferiu-se realizar as comparações entre médias da variável apego ao lugar por meio do teste $t$ de Student.

Nota-se, a partir dos resultados, que não foi encontrada diferença estatisticamente significativa $[t(162)=-1,831 ; p$ $=0,069$ ] entre os grupos de meninas $(M=3,34 ; D P=0,509)$ quando comparados com os meninos $(M=3,19 ; D P=0,616)$. Mesmo este resultado não sendo significativo em termos estatísticos, é possível considerá-lo como um resultado sugestivo, o que pode ser a sinalização de uma diferença de fato existente se comparado com realidade semelhante. Por exemplo, uma pesquisa realizada em âmbito brasileiro com o objetivo de identificar os lugares favoritos dos adolescentes no contexto brasiliense, verificou diferenças significativas entre meninos e meninas em função dos diferentes espaços de interação a exemplo da escola, tendo os meninos apresentado menor preferência pelo espaço escolar do que as meninas $\left(X_{\mathrm{gl}=1}^{2}=14,27, p<0,001\right)$. Outros espaços também diferenciados em termos de preferência entre meninos e meninas nessa pesquisa foram: hospitais, transportes públicos e lugares agitados (Günther \& cols, 2003). 
Resultados relativos à comparação do nível de apego ao lugar em função do sistema de ensino

Os resultados seguem com a análise de comparação com a finalidade de atender ao último objetivo específico do estudo, que é comparar os grupos em função do sistema de ensino (público e particular) verificando a existência de significativas diferenças. Mais uma vez, optou-se por realizar as comparações entre médias da variável apego ao lugar por meio do teste $t$ de Student.

Nesse sentido, os indivíduos do sistema de ensino público $(M=3,19 ; D P=0,503)$ apresentaram menor indicador de apego ao lugar quando comparados com os estudantes do sistema de ensino particular $(M=3,36 ; D P=0,603)$, sendo este resultado estatisticamente significativo $[t(198)=$ $2,205 ; p=0,029]$. As escolas tanto públicas quanto privadas desempenham estruturas fundamentais para o ensino e o desenvolvimento dos estudantes, a partir de pontos principais que envolvem a segurança, o conforto e as atividades desenvolvidas no espaço escolar. Portanto, as atividades recreativas oferecidas pelas escolas são de tamanha importância para o crescimento psicológico, social e relacional dos estudantes, tendo em vista a construção de interações e apego com o ambiente e com as pessoas participativas deste espaço (Raymundo, Kuhnen, \& Soares, 2010).

No entanto, de acordo com esses resultados, é possível discutir que há diferença no oferecimento de estrutura e serviços que podem interferir na relação entre o usuário e o espaço em análise. De forma geral, os questionamentos realizados nos objetivos foram atendidos nesta seção, e como já haviam sido contempladas em todo o corpo teórico do artigo, as comparações entre os grupos concordaram com os achados de pesquisas anteriores. Os resultados ainda sugeriram a possibilidade de respostas interessantes no caso de comparação de grupo para a necessidade de estratégias de ação voltadas para a promoção de identidade com a escola, percepção da escola como comunidade e atitudes positivas frente à escola.

\section{Considerações Finais}

O presente artigo atendeu aos objetivos propostos, a saber: 1) conhecer o nível de apego dos alunos com o ambiente escolar e 2) verificar se existe diferença em função do sexo e do sistema de ensino público e particular. Consistentemente com tais objetivos, constatou-se que todos os questionamentos foram atendidos na seção dos resultados.

Embora esteja claro o atendimento aos objetivos traçados, alguns pontos do estudo precisam ser destacados como fatores limitantes. Em primeiro lugar, é importante ressaltar que a opção por uma amostra de conveniência se deu em decorrência do pouco tempo disponível para o levantamento dos dados, mesmo sabendo que uma amostra aleatória poderia auxiliar em um levantamento de dados mais precisos sobre a temática estudada.
Este estudo possui a característica de ser ainda preliminar, pois se baseia em conhecer o nível de apego dos alunos ao ambiente escolar, o que é fundamental e pode ser visto como um ponto de partida para outras contribuições sobre o entendimento do apego à escola, a partir da variável selecionada: apego ao lugar. $\mathrm{O}$ intuito do estudo desenvolvido é, portanto, mostrar a questão do aluno que cria laços afetivos com a escola, a partir de um ambiente prazeroso e as repercussões desse elo afetivo nos processos educacionais, no desenvolvimento humano e da aprendizagem desde um aspecto mais gera, o que parece ser um elemento positivo à promoção da qualidade de ensino, assim como para a manutenção do patrimônio escolar (Dessen \& Polonia, 2007).

Foram referenciadas pesquisas que trazem como variável relevante para a explicação de apego, principalmente no campo de estudo da Psicologia, apego ao lugar e laços afetivos criados com o ambiente escolar. Consequentemente, é notável a pertinência da reflexão relacionada com o apego escolar a partir da verificação da associação com a variável citada.

Diante disso, também traz contribuições à Psicopedagogia, por ser um estudo precursor da temática no panorama de conhecimento psicopedagógico. A Psicopedagogia, como campo de atuação preocupado com os processos de aprendizagem, considera a possibilidade de a escola ser entendida como um ambiente de formação acadêmica, afetiva e social; discorrendo quanto à questão que as emoções influenciam positiva e negativamente a vida de um estudante dependendo do ambiente no qual está inserido, permitindo que cada usuário discorra de suas atitudes e percepções de forma objetiva e direta (Bossa, 2011; Felippe \& Kuhnen, 2012).

Conclui-se, portanto, que há um leque de possibilidades de aplicações das contribuições deste estudo para a Psicopedagogia, desde a vertente institucional, assim como também para áreas da Psicologia e da Pedagogia. Inicialmente, ressalta-se a relevância do estudo como um conhecimento interessante para o entendimento dos entraves envolvidos na aprendizagem provenientes do apego ao lugar e de suas possíveis ligações com laços afetivos criados por estudantes no âmbito institucional. Campanhas de intervenção também podem ser pensadas para a equipe docente e a escola como um todo, esclarecendo as dúvidas sobre o apego ao lugar e as suas ligações com os estudantes e a escola; focalizando os esforços para a promoção de uma aprendizagem de qualidade que, uma vez atenta aos elementos quanto aos laços afetivos e seu poder de modificação do comportamento, é capaz de favorecer o crescimento pleno desse (novo) sujeito social.

\section{Referências}

Alencar, H. F. D. \& Freire, J. C. (2007). O lugar da alteridade na psicologia ambiental. Revista Mal Estar e Subjetividade, 7(2), 305328. 
Balarine, O. F. O. (2002). Tecnologia da informação como vantagem competitiva. RAE-eletrônica, 1(1), 1-11.

Bossa, N. (2011). A Psicopedagogia no Brasil: contribuições a partir da prática. São Paulo: Wak.

Bowlby, J. (1977). The making and breaking of affectional bonds. A etiology and psychopathology in the light of attachment theory. An expanded version of the Fiftieth Maudsley Lecture, delivered before the Royal College of Psychiatrists, 19 November 1976. The British Journal of Psychiatry, 130(3), 201-210.

Cavalcante, S. \& Nóbrega, L. M. (2011). Espaço e lugar. Temas básicos em psicologia ambiental. Petrópolis: Vozes.

Cunha, J. E. M. (2013). Os valores humanos como preditores da percepção da escola como comunidade. Trabalho de Conclusão de Curso não publicado, Universidade Federal da Paraíba, João Pessoa.

Dalbem, J. X. \& Dell'Aglio, D. D. (2005). Teoria do apego: bases conceituais e desenvolvimento dos modelos internos de funcionamento. Arquivos brasileiros de psicologia, 57(1), 12-24.

Dayrell, J. (2007). A escola "faz" as juventudes? Reflexões em torno da socialização juvenil. Educação e Sociedade, 28(100), 11051128.

Delors, J., Al-Mufti, I., Amagi, I., Carneiro, R., Chung, F., Geremek, B., Gorham, W., Kornhauser, A., Manley, M., Quero, M. P., Savané, M. A., Singh, K., Stavenhagen, R., Suhr, M. W., \& Nanzhão, Z. (1998). Educação um tesouro a descobrir. Relatório para a Unesco da comissão internacional sobre educação para o século XXI. Recuperado: 22 de jan. 2014. Disponível: http://dhnet.org.br/ dados/relatorios/a_pdf/r_unesco_educ_tesouro_descobrir.pdf.

Dessen, M. A. \& Polonia, A. D. C. (2007). A família e a escola como contextos de desenvolvimento humano. Paidéia, 17(36), 21-32.

Eccheli, S. D. (2008). A motivação como prevenção da indisciplina. Educar, (32), 199-213.

Elali, G. A. \& Medeiros, S. T. F. (2011). Apego ao lugar. Em S. Cavalcante \& G. A. Elali (Orgs.). Temas básicos em Psicologia Ambiental. Rio de Janeiro: Vozes.

Faria, J. I. L. \& Casagrande, L. D. R. (2004). A educação para o século XXI. Revista Latino-americana de Enfermagem, 12(5), 821-7.

Felippe, M. L. \& Kuhnen, A. (2012). O apego ao lugar no contexto dos estudos pessoa-ambiente: práticas de pesquisa. Estudos de Psicologia, 29(4), 609-617.

Felippe, M. L., Raymundo, L. S., \& Kuhnen, A.(2013). Investigando laços afetivos com a escola a partir de mapas ambientais. Estudos e Pesquisas em Psicologia,13(3), 1010-1038.
Figueiredo, C. (2010). Novo Dicionário de Língua Portuguesa de Cândido de Figueiredo (Vol. 2). Portugal. Recuperado: 16 de jan. 2014. Disponível: http://www.gutenberg.org/files/31552/31552-pdf. pdf.

Giuliani, V. M. (2004). O lugar do apego nas relações pessoasambiente. Em E. T. O. Tassara, E. P. Rabinovich, \& M. C. Guedes (Orgs.), Psicologia e ambiente (pp. 89-106). São Paulo.

Giuliani, M. V., Tassara, E. T. O., Rabinovich, E. P., \& Guedes, M. C. (2004). O lugar do apego nas relações pessoas-ambiente. Psicologia e ambiente, 1, 89-106.

Guimarães, S. E. \& Boruchovitch, E. (2004). O estilo motivacional do professor e a motivação intrínseca dos estudantes: uma perspectiva da teoria da autodeterminação. Psicologia: Reflexão e Crítica, 17(2), 143-150.

Günther, I. A., Nepomuceno, G. M., Spehar, M. C., \& Günther, H. (2003). Lugares favoritos de adolescentes no Distrito Federal. Estudos de Psicologia, 8(2), 299-308.

Kaiser, F. G. \& Fuhrer, U. (1996). Dwelling: Speaking of an unnoticed universal language. New Ideas in Psychology, 14(3), 225-236.

Klodzinski, D., Arnas, F., \& Ribas, A. (2005). O ruído em salas de aula de Curitiba: como os alunos percebem este problema. Revista Psicopedagogia, 22(1), 105-110.

Lei n. 9394, de 20 de dezembro de 1996 (1996, 20 de dezembro). Estabelece Diretrizes e Bases da Educação Nacional). Recuperado: 12 de fev. 2014. Disponível: http://www. planalto. gov.br/ccivil 03/ leis/19394. htm.

Li, M. Y. (2011). Place attachment in university students: social antecedents and academic motivations. Doctoral dissertation ou Master's Thesis. University of Pittsburgh, Estados Unidos.

Libardi, A., Gonçalves, C. G. O., Vieira, T. P. G., Silverio, K. C. A., Rossi, D., \& Penteado, R. Z. (2006). O ruído em sala de aula e a percepção dos professores de uma escola de ensino fundamental de Piracicaba. Distúrbios da Comunicação, 18(2), 167-178.

Oliveira-Silva, J. (2008). O aluno, a escola, o professor: relações do aprender. Saber Acadêmico, 6.

Panizzi, C. A. F. L. (2010). A Relação Afetividade-Aprendizagem no cotidiano da sala de aula: enfocando situações de conflito. Espaço Psicopedagógico. Jan.

Porto, O. (2011). Psicopedagogia institucional: teoria, prática e assessoramento psicopedagógico. Rio de Janeiro: Wak.

Raymundo, L. S., Kuhnen, A., \& Soares, L. B. (2010). O espaço aberto da educação infantil: lugar para brincar e desenvolver-se. Psicologia em Revista, 16(2), 251-270. 
Relph, E. (1970). An inquiry into the relations between phenomenology and geography. The Canadian Geographer/Le Géographe canadien, 14(3), 193-201.

Ribeiro, M. E. R., Oliveira, R. L. D. S., Santos, T. M. M., \& Scharlach, R. C. (2010). A percepção dos professores de uma escola particular de Viçosa sobre o ruído nas salas de aula. Revista Equilibrio Corporal e Saúde, 2(1), 27-45.
Scannell, L. \& Gifford, R. (2010). Defining place attachment: A tripartite organizing framework. Journal of Environmental Psychology, 30(1), 1-10.

Sutton, S. E. \& Kemp, S. P. (2002). Children as partners in neighborhood place making: lessons from intergenerational design charrettes. Journal of Environmental Psychology, 22(1), 171-189.

\section{Sobre as autoras}

Pollyana Verissimo de Araújo (polly-14@hotmail.com)

Universidade Federal da Paraíba; Graduada em Psicopedagogia.

Viviany Silva Pessoa (viviany.pessoa@gmail.com)

Universidade Federal da Paraíba; Doutorado em Psicologia.

Patricia Nunes da Fonseca (pnfonseca.ufpb@gmail.com)

Universidade Federal da Paraíba; Doutorado em Psicologia.

Juliana Henrique de Assis Albuquerque (juhalbuquerque@hotmail.com) Universidade Federal da Paraíba; Graduação em Psicopedagogia.

Aline Carvalho de Almeida(alinealmeidapb@hotmail.com)

Universidade Federal da Paraíba; Mestranda em Psicologia Social.

Origem derivado de monografia. 